\title{
Analysis of dry cover systems composed of tropical soils for mining waste
}

\author{
DA Perotti Universidade de São Paulo, Brazil \\ GFN Gitirana Jr Universidade Federal de Goiás, Brazil \\ MD Fredlund SoilVision Systems Ltd., Canada
}

\begin{abstract}
The flow of water in mining tailings and waste rock may cause serious environmental impacts associated with acid rock drainage. Soil cover systems have been used to control or minimise such damages. In relatively dry climates, 'store-and-release' covers, also known as dry covers, have been considered as feasible alternatives. The objective of this paper is to evaluate the influence of atmospheric conditions and soil type in the performance of dry cover systems, considering conditions typical of tropical climates found in Brazil's central-west region. Numerical analyses using the finite element method were performed considering four different systems composed of tropical soils. Among the proposed arrangements, three use a soil that presents a bimodal soil-water characteristic curve and the fourth cover employs a unimodal soil. The thicknesses of intermediate materials were varied, and different representative precipitation parameters were considered for a period of one year. The results obtained were compared in terms of the internal flow and the capacity of the system to store water. The results indicate that bimodal soils may not be ideal cover materials and require specific compaction conditions that would reduce their macropores. Unimodal tropical soils presented adequate response as store-and-release materials. The use of an intermediate layer acting as a capillary barrier did not offer significant improvement to the cover systems evaluated.
\end{abstract}

Keywords: cover systems, dry covers, tropical soils, finite element method

\section{Introduction}

The mining waste disposal projects have as their main goal to minimise environmental impacts caused by effluent flow, which often involves acid rock drainage (ARD). ARD is the result of oxidation of mining waste composed of sulphide minerals and requires the presence of water and oxygen (MEND 2004; Adu-Wusu \& Yanful 2006). The resulting acidic aqueous solution leaches the sulphate materials present in the waste, producing a percolate rich in dissolved metals and sulphuric acid. This solution may cause serious environmental impacts if it reaches water bodies, making the water unfit for use for long periods of time after mine decommissioning (Amorim 2008). A very common form of storage of solid mining wastes is through piles arranged directly above the natural ground. For this type of system, it is usual to adopt soil cover systems. In addition to controlling the generation of ARD, cover systems must also provide protection against erosion and dust, sustain vegetation, and allow traffic (Duarte 2012).

The design of cover systems is multi-disciplinary, involving the combination of several areas of engineering, plant physiology and agricultural science (Interstate Technology \& Regulatory Council [ITRC] 2003). The quantification of water and airflows through cover systems requires the understanding and modelling of the interaction between the soil and the atmosphere. Unsaturated soil mechanics theories become of paramount importance, since dry cover systems are designed to work predominantly in this condition (Fredlund 2002). It is, therefore, a problem that involves numerous physical mechanisms and parameters, which when combined result in a high degree of complexity. 
The mining industry in Brazil deals with cover materials that have peculiar behaviour. Highly weathered soils in Brazil often present clay aggregates that result in bimodal soil-water characteristic curves (SWCC) (Gitirana Jr \& Fredlund 2004). These materials have unique hydraulic behaviour that is highly dependent on the manner of how the soil is prepared and compacted. In this context, this paper aims to quantify and discuss the influence of parameters such as soil type under typical local atmospheric conditions on the performance of cover systems using tropical soils. Four cover systems are proposed, using the tropical soil compacted under different conditions, allowing an identification of optimum cover designs.

\section{Materials and methods}

There are various arrangements and types of cover systems, and several factors can influence the choice of cover type adopted in a project. However, the site climate condition is the preponderant factor influencing design. For example, it is difficult to construct a cover system that contains a highly saturated layer for reducing oxygen transport in arid and semi-arid sites. This cover system will be subject to extensive drought periods and, therefore, evaporation would be quite significant. However, if the goal is to reduce the infiltration of water into the underlying layers, exposing the cover system to high evaporation demand becomes beneficial to the performance of the system (O'Kane et al. 2002). The main types of existing cover systems are: (a) storage and release systems that have enough storage capacity to retain water during rainy periods; (b) systems with low permeability layers consisting basically of a compacted soil layer (O'Kane et al. 2002); (c) systems employing a capillary barrier that restricts the passage of water to the larger pores of the lower layer (Silva 2011).

Some soil cover arrangements presented by O'Kane et al. (2002) are shown in Figure 1 . The base method uses a layer of generally non-compacted native material directly overlaying the waste pile. Its main objective is to establish sustainable vegetation cover, but the reduction of percolation is considered a secondary benefit. Other configurations may be established, making use of the concepts of storage layer, low permeability barrier and capillary barrier. For example, an uncompacted layer or a vegetation growth medium may be used over a compacted layer. In this case, the upper layer will act as a storage and release layer and the compacted layer will help the upper layer store water for a longer period of time until the end of the evaporation (O'Kane et al. 2002).

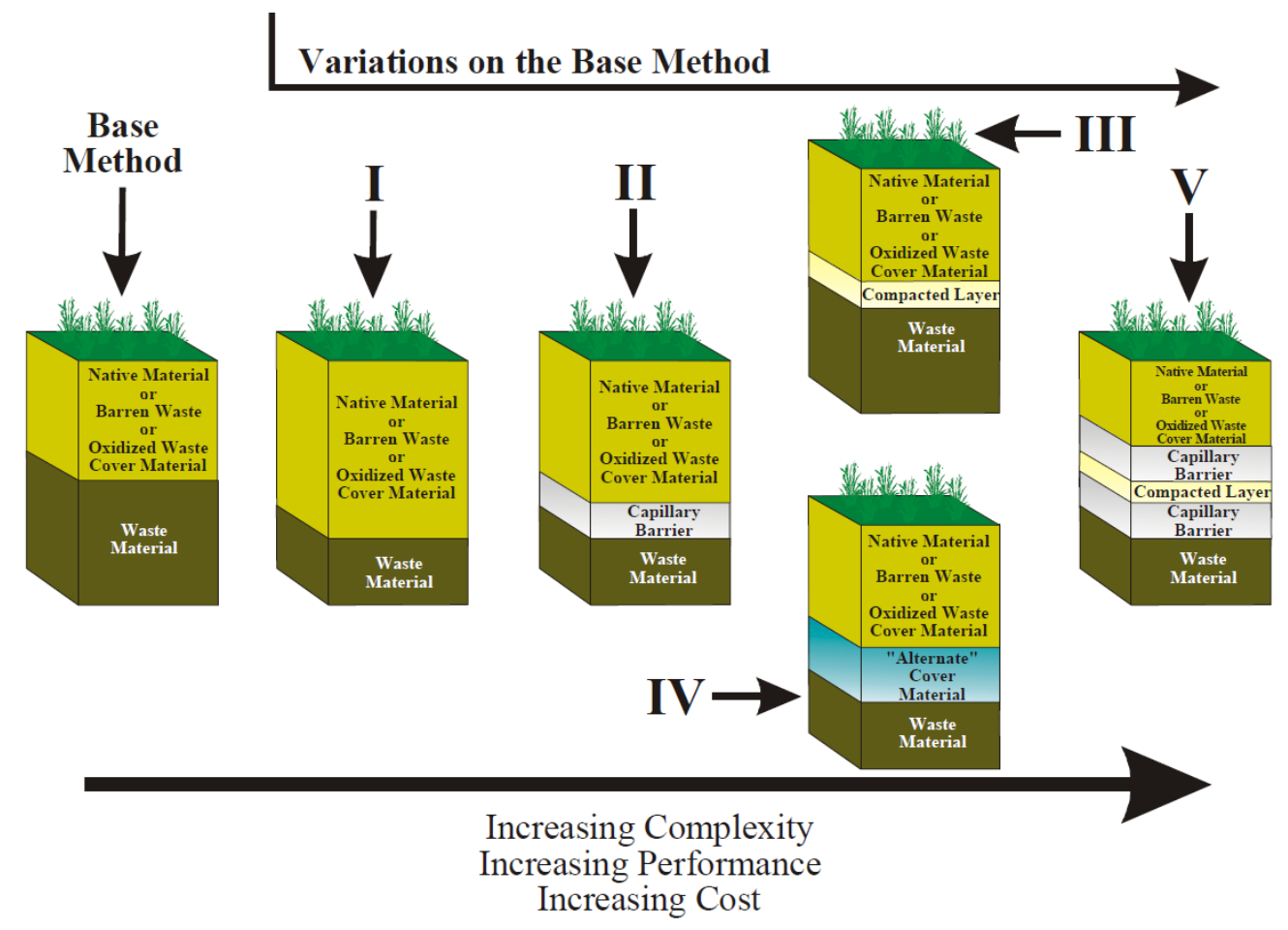

Figure 1 Schematic illustration of the base method cover system and variations of the base method (O'Kane et al. 2002) 


\subsection{Cover system modelling and design}

As the cover system is in direct contact with the atmosphere, knowledge and understanding of the hydrological cycle and site climate conditions is essential. Figure 2 shows a scheme of soil-atmosphere interactions in a soil cover, presenting the main components of the hydrological cycle that should be analysed. These data are fundamental in the design stage because they will be used as boundary conditions in the numerical analysis.

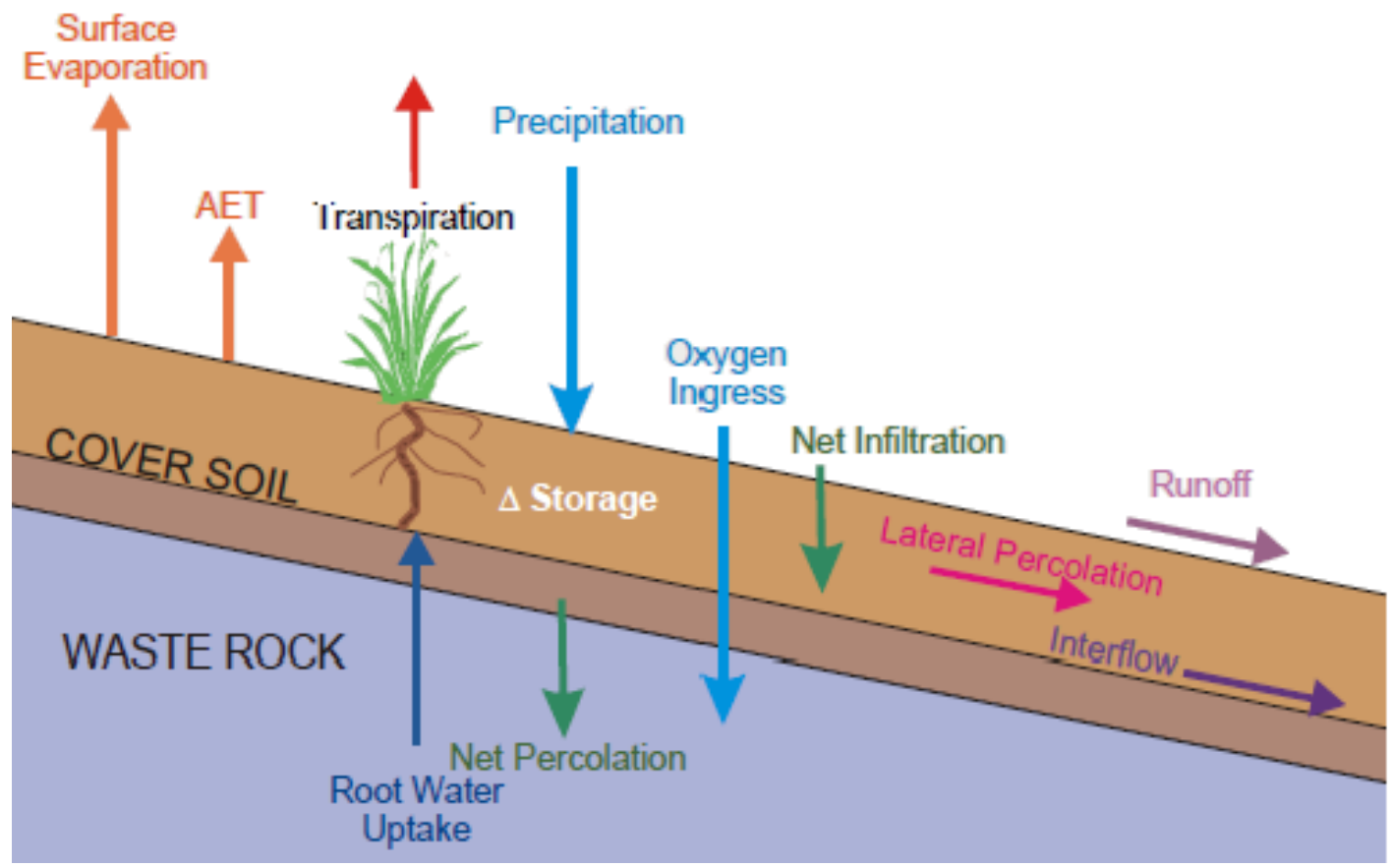

Figure 2 Conceptual scheme of components analysed in a cover system (O'Kane et al. 2002)

Water from precipitation that reaches the surface may seep into the soil or flow over the surface. This will depend on soil storage capacity and its infiltration capacity. If the precipitation rate exceeds the soil infiltration capacity, the surplus becomes runoff. This relationship between precipitation, infiltration and runoff is shown in Figure 3.

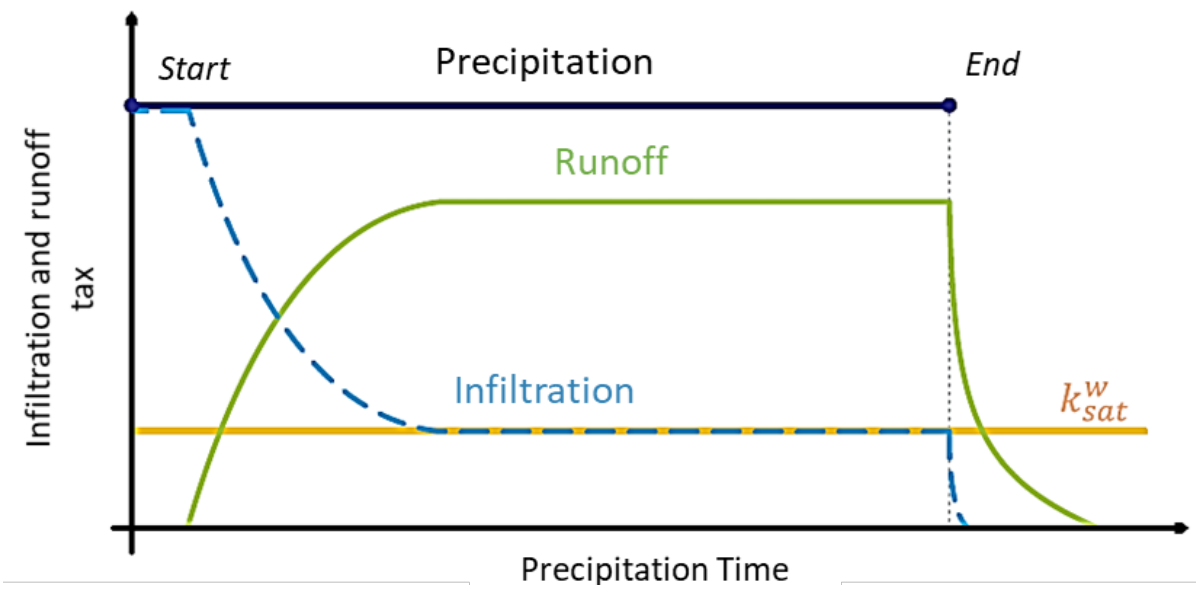

Figure 3 Mechanism of water infiltration into the soil (Silva Júnior 2015) 
The hydrological cycle is usually studied in the context of a watershed. This watershed can be considered as a physical system subject to the inputs (precipitation) and outputs (runoff and evaporation), resulting in a water balance. The evaporation is divided in two types, namely: potential and actual evaporation. The potential evaporation occurs from water bodies or saturated soil surfaces and the actual evaporation takes place from unsaturated soil surfaces (Collischonn \& Tassi 2008). The water balance can be described by Equation 1.

$$
N F=P-A E-R
$$

where:

$$
\begin{aligned}
& N F=\text { net flow. } \\
& P \quad=\text { precipitation. } \\
& A E=\text { actual evaporation. } \\
& R \quad=\text { runoff. }
\end{aligned}
$$

The net flow (NF) corresponds to the natural boundary condition to be employed in the analysis of cover systems. Precipitation $(P)$ is obtained based on climatological data. Actual evaporation $(A E)$ and runoff $(R)$ may be obtained using climatological data or obtained using methods based on secondary atmospheric and soil data (Gitirana Jr et al. 2006). A very common way of calculating potential evaporation in a monthly time interval is through the Thornthwaite equation, based on temperature data. The results obtained by this equation are very satisfactory for wetland locations, but in arid conditions this model provides results that often underestimate potential evaporation. To correct this underestimation, a correction can be applied from the daily temperature range, calculating an effective mean temperature (Camargo \& Camargo 2000). This correction method will be referred to in this work as modified Thornthwaite. After obtaining the potential evaporation, the actual evaporation may be determined based on the suction of the soil surface (Wilson 1990).

\subsubsection{Soil-water characteristic curve}

The soil-water storage capacity is represented by the SWCC, which can be defined as the relationship between the soil-water content and soil suction (Fredlund et al. 1994). There are three notable points in a SWCC: the air entry value (AEV), the slope of the SWCC and the residual water content. The AEV is the suction needed to overcome the capillary forces of the largest pores in the soil. The slope of the SWCC describes the water loss rate with suction after the AEV is exceeded. The residual water content refers to the water content in which suction is no longer effective in removing water from the soil in the liquid state. This behaviour is observed mainly because the soil hydraulic conductivity decreased as the soil loses water (Fredlund \& Rahardjo 1993).

Several fitting curves are available to represent SWCC data. Among the proposed methods is the equation proposed by Gitirana Jr \& Fredlund (2004). This equation is of interest in the modelling of tropical soils because it allows the modelling of bimodal and unimodal curves. The best-fit parameters are the residual suction, the air entry value, the residual saturation and a parameter that controls the curve smoothness. The general format of the family of equations is as follows:

$$
S=\frac{S_{1}-S_{2}}{1+\left(\frac{\psi}{\sqrt{\psi_{b 1} \psi_{\text {res } 1}}}\right)^{d 1}}+S_{2}
$$

where:

$$
\begin{aligned}
& S=\text { degree of saturation. } \\
& \psi_{\text {res }}=\text { residual suction }(\mathrm{kPa}) . \\
& \psi_{b}=\text { air entry value }(\mathrm{kPa}) . \\
& d \quad=\text { weight factor. }
\end{aligned}
$$




\subsubsection{Partial differential equation governing water flow and balance}

In addition to being found in the soil pores in the liquid phase, water can also be found in the vapour state. As a result, another relevant flux mechanism in the soil is the airflow (Gitirana Jr et al. 2012). However, the only flow mechanisms that will be considered herein will be those related directly to water, the flow of liquid water and the flow of vapour water.

The flow of liquid water in an unsaturated soil is governed by Darcy's Law. However, for unsaturated soils, the permeability coefficient is not constant but a function of soil-water content or soil suction (Fredlund \& Rahardjo 1993). The flow of vapour water through the soil may take place in terms of two mechanisms: by diffusion and by advection within moving air. Neglecting airflow and thermal gradients, the vapour water flow is given by Fick's Law (Fredlund \& Gitirana Jr 2005). Thus, the flow of water in the soil becomes the sum of the components of liquid water and vapour water. Equation 3 describes the flow and the mass balance of water, considering one-dimensional flow (Fredlund \& Gitirana Jr 2005):

$$
\frac{\partial}{\partial y}\left[k_{w} \frac{\partial}{\partial y}\left(\frac{u_{w}}{\gamma_{w}}+y\right)+\frac{k^{v d}}{\gamma_{w}} \frac{\partial u_{w}}{\partial y}\right]=\frac{d \theta}{d t}
$$

where:

$$
\begin{aligned}
& k_{w}=\text { hydraulic conductivity. } \\
& u_{w}=\text { porewater pressure. } \\
& \gamma_{w}=\text { unit weight of water. } \\
& y \quad=\text { elevation. } \\
& k^{v d}=\text { porewater vapour conductivity by vapour diffusion within the air phase. } \\
& \theta \quad=\text { volumetric water content. }
\end{aligned}
$$

\subsubsection{Numerical analysis tool}

For analysis of the one-dimensional flow in defined cover systems, the partial differential equations governing the system were solved using the SVFlux-GE and FlexPDE numerical tools. From a script-based formulation, these tools perform the operations necessary to create a finite element model (FEM), solving the system and presenting graphical outputs. The software uses the FEM and the finite difference method combined with the Newton-Raphson iterative method for solving nonlinear problems. It uses a wide range of functions required to solve partial equation systems (PDE Solutions 2008).

\subsubsection{Cover design criteria}

The performance of a cover system can be quantified in terms of resulting (net) percolation that reaches the waste pile. The net percolation, as shown in Figure 2, is the water from the precipitation that infiltrates the surface of the cover material and reaches the waste. A cover system is necessarily designed to completely prevent the flow of water into the waste layer. Sometimes, considering the characteristic of the waste material, a percentage of net percolation is allowed. In this way, it is necessary to establish acceptable flow values. The Canada Centre for Mineral and Energy Technology manual (O'Kane et al. 2002) classifies as 'moderate quality' a cover system that allows a net percolation of approximately $11 \%$ of the average annual precipitation, and of 'high quality' a cover that allows a net percolation lower than $2 \%$. 


\subsection{Cover systems analysed and input parameters}

There are several possible arrangements for cover systems, with varying degrees of complexity. The geometries of the systems that will be analysed herein are presented in Figure 4. Among the arrangements originally presented in Figure 1, four designs will be analysed: the base method (S1), two models for the variation II (S2 and S4) and the variation III (S3). These designs were chosen because they are 'primary' arrangements. Only after analysing the simplified systems, and knowing how each of these different alternatives behaves, it is possible to create more complex alternatives. For all models, a $750 \mathrm{~cm}$ waste layer was considered.

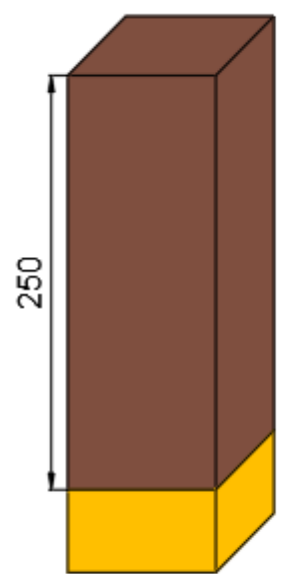

S1

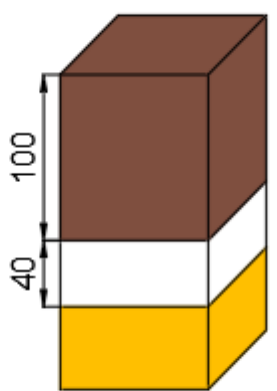

S2

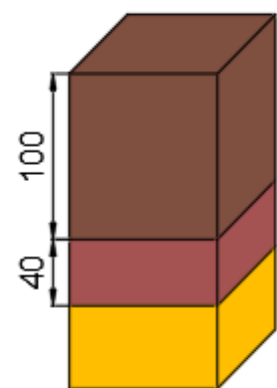

S3

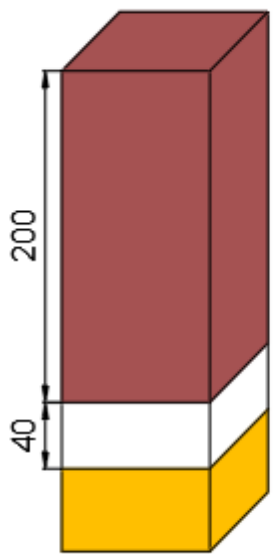

S4

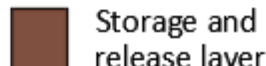

release layer

Compacted layer

Capillary barrier

Waste layer

Figure 4 Cover system arrangements considered (dimensions measured in centimetres)

\subsubsection{Material properties}

The soils that will be used for the storage and release layers and for the compacted layer are tropical soils typical of the city of Goiânia, Goiás, Brazil. For the storage and release layers, the soil is considered to be uncompacted or poorly compacted. A fine sand was chosen for the capillary barrier. The waste material is phosphogypsum, a by-product of phosphoric acid production. The physical characteristics of the materials, such as liquid limits $\left(w_{L}\right)$, plastic limit $\left(W_{P}\right)$, plasticity index $\left(I_{p}\right)$, specific weights $\left(\gamma_{d}\right)$, void ratios $(e)$ and saturated hydraulic conductivities $\left(k_{\text {sat }}\right)$ are presented in Table 1.

Table 1 Properties of the materials of the cover systems

\begin{tabular}{lcccccc}
\hline Material & $\mathbf{W}_{\mathrm{L}}(\%)$ & $\mathbf{W}_{\mathrm{P}}(\%)$ & $\mathbf{I}_{\mathrm{P}}(\%)$ & $\mathbf{V}_{\mathrm{d}}\left(\mathbf{k N} / \mathbf{m}^{\mathbf{3}}\right)$ & $\mathbf{e}$ & $\mathbf{k}_{\text {sat }}(\mathbf{m} / \mathbf{s})$ \\
\hline Unimodal soil & 45 & 27 & 18 & 16.8 & 0.620 & $1.6 \times 10^{-7}$ \\
Bimodal soil & 35 & 25 & 10 & 15.4 & 1.700 & $7.8 \times 10^{-6}$ \\
Sand & - & - & - & 15.4 & 0.660 & $1.2 \times 10^{-4}$ \\
$\begin{array}{l}\text { Phosphogypsum } \\
\text { w }\end{array}$ & - & - & - & 12.1 & 1.110 & $2.4 \times 10^{-6}$ \\
conductivities.
\end{tabular}

The grain size distribution curves of the tropical soils were obtained from Angelim (2011). These soils were also studied by Kühn (2014). The properties of the phosphogypsum were obtained by Matos (2011) and the properties of the sand were obtained by Silva (2011). For tropical soils and for phosphogypsum, the authors performed sedimentation tests with deflocculant (D) and without deflocculant (ND), as shown in Figure 5(a). The material studied by Leão Carvalho (2013) was chosen for the storage and release layer. This is bimodal soil. The material studied by Kühn (2014), which is a unimodal soil, was selected for the compacted layer. The SWCC of all the materials are shown in Figure $5(b)$. 
a)

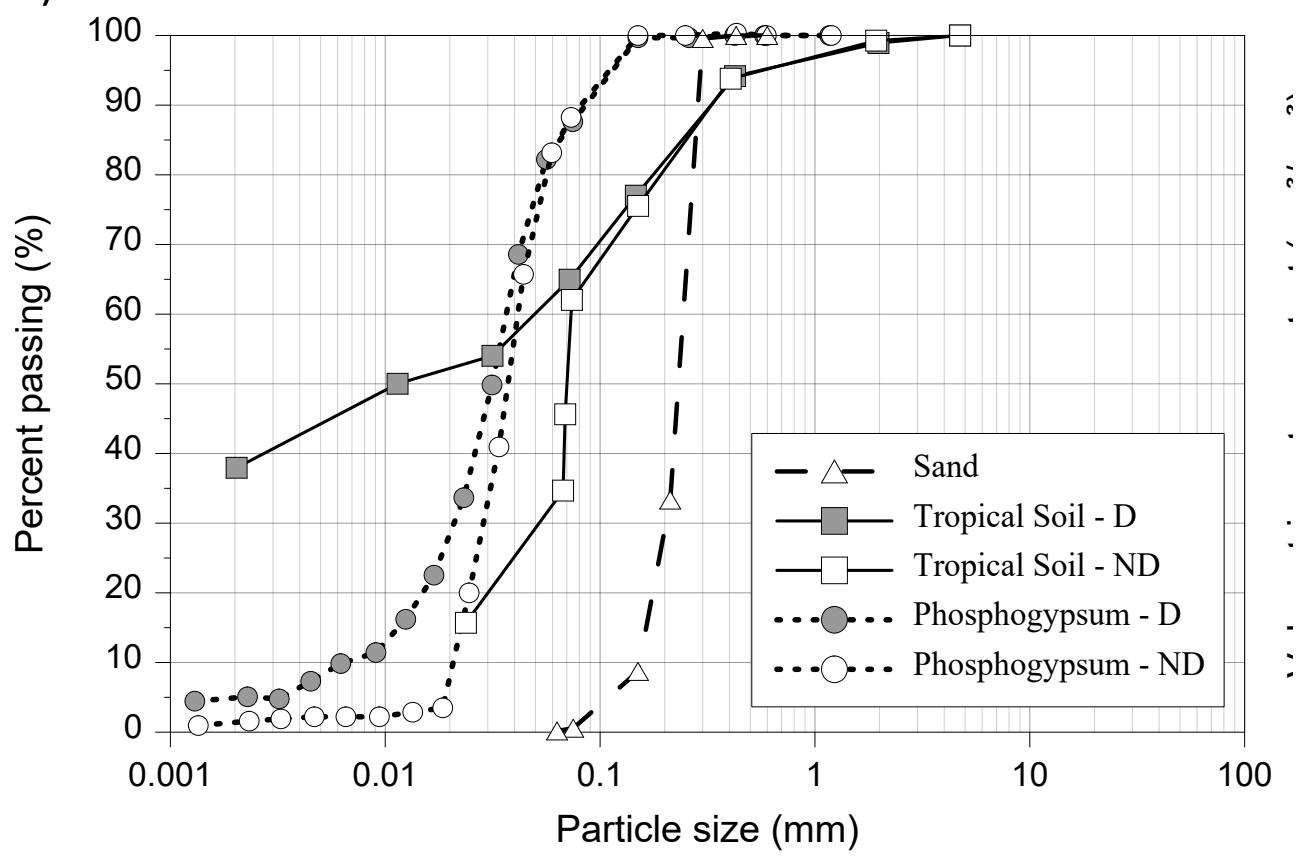

D)

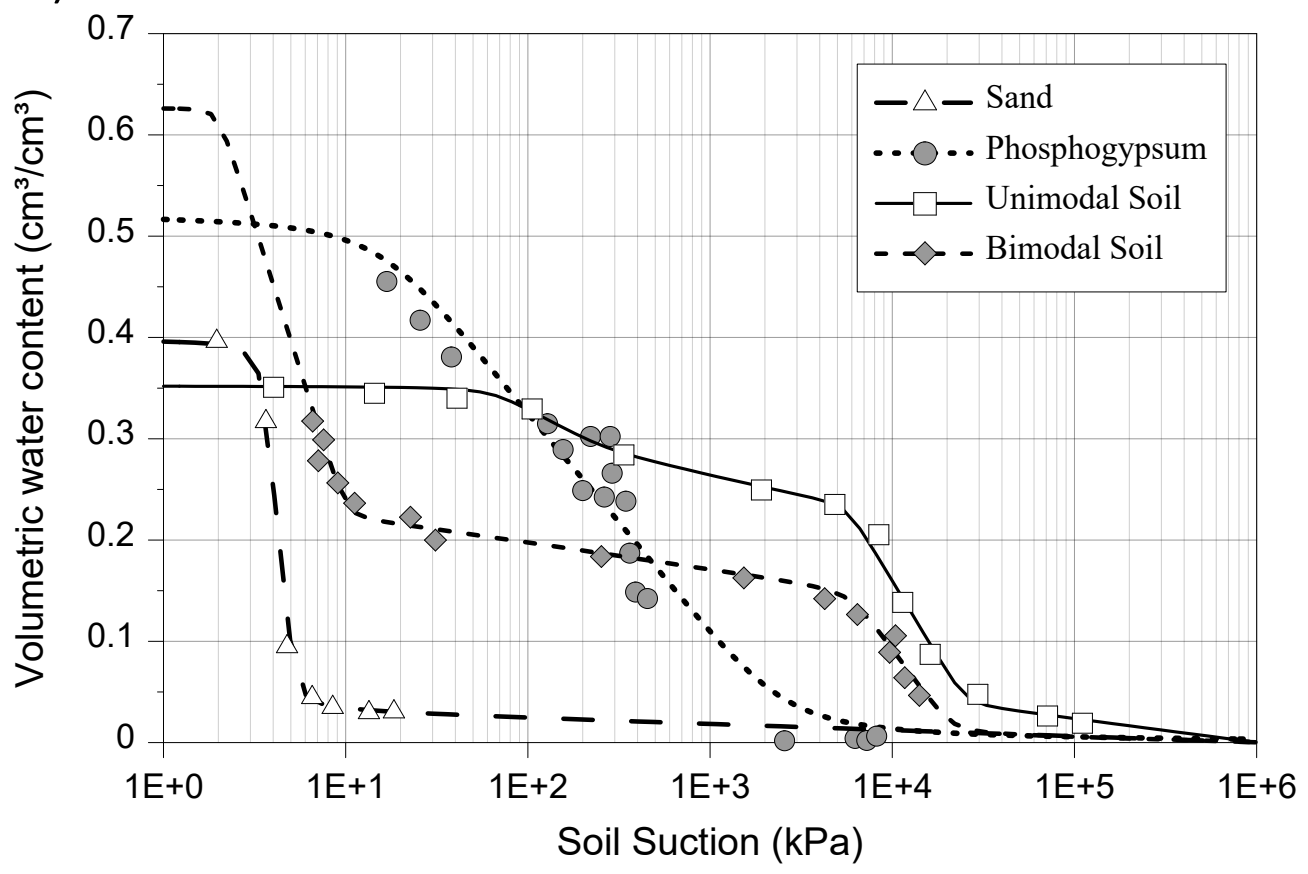

Figure 5 Soil properties: (a) grain size distribution curves; (b) soil-water characteristic curves

\subsubsection{Atmospheric conditions}

The region selected for this study was the city of Goiânia, Goiás, Brazil. The weather data for the year 2011 was organised by Silva Júnior (2015), as presented in Figure 6 . The average daily temperature data will be used to calculate potential evaporation using the Thornthwaite method. Actual evaporation will be calculated using the relative humidity and potential evaporation data and the formulation proposed by Wilson (1990). 

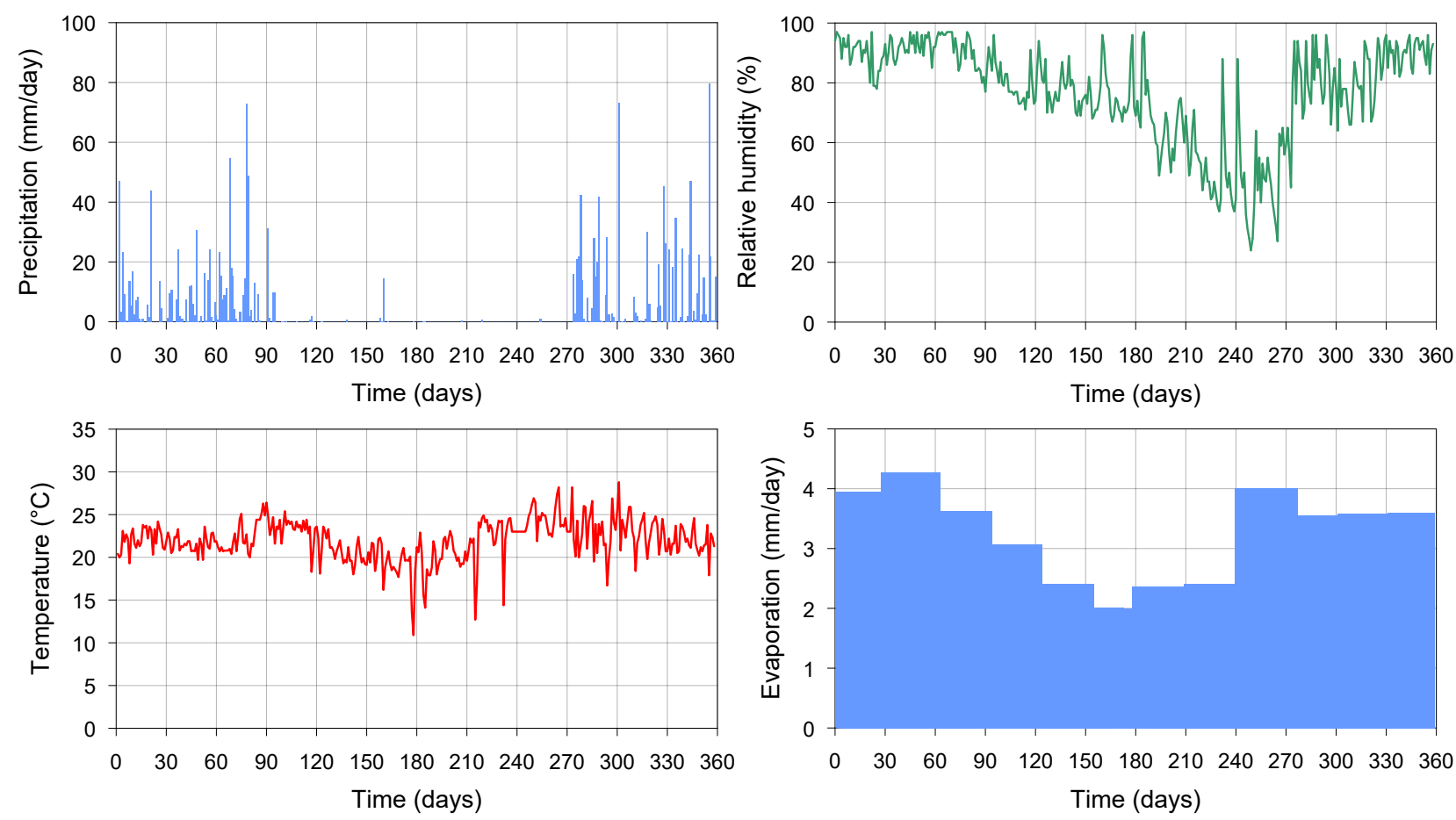

Figure 6 Atmospheric data (modified from Silva Júnior 2015)

\section{Results and discussions}

Automatic meshing and time-stepping procedures were employed to assess the quality of the numerical computations. Relatively fine meshes and small time-steps are required to solve the highly nonlinear characteristics imposed by the steep SWCC of some of the materials. One of the main parameters used to verify that results are accurate is the relative mass balance error. Figure 7 presents the error over the entire analysis period. Rainfall periods that required the computation of runoff produce larger errors. For example, a significant increase is seen in all analyses at day 275 , approximately. At this moment, the rainy season starts, after a long period of drought. The typical duration of the computations was approximately 24 hours, using an Intel 5th generation i5 mobile processor.

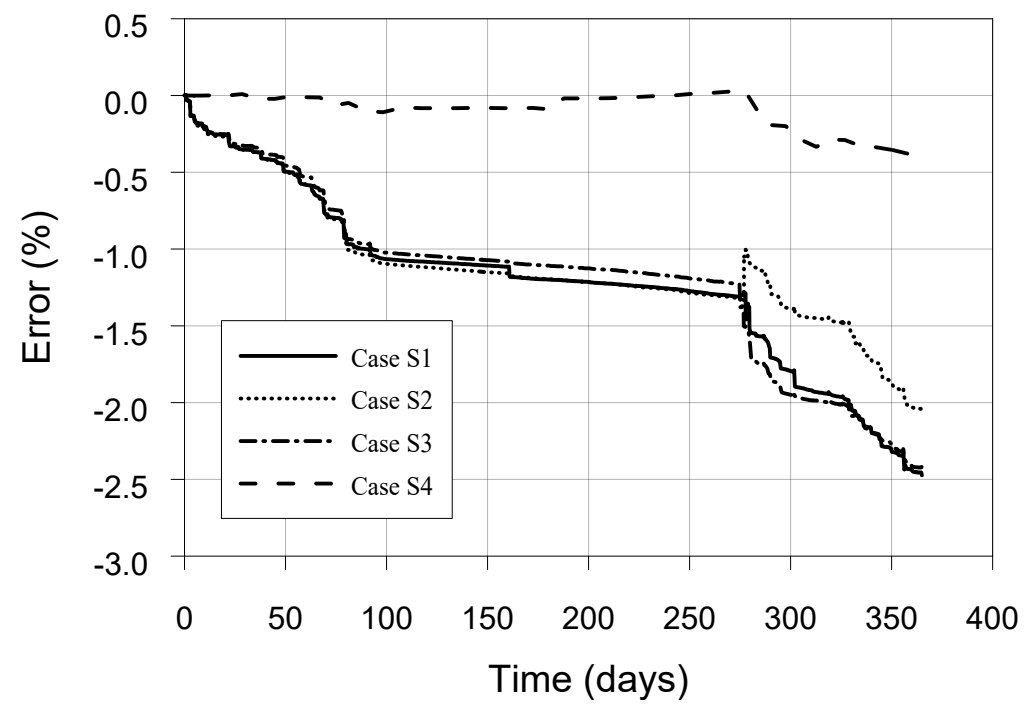

Figure 7 Mass balance errors 


\subsection{Influence of precipitation intensity}

Available atmospheric data generally contains limited information, particularly with respect to rainfall intensity. At the same time, the amount of surface runoff depends heavily on the precipitation intensity. Thus, in order to evaluate the influence of the rain intensities considered in a cover system design, different values of rainfall duration were applied to the same system, thus promoting rainfall with the same accumulated volume, but with different intensities. Figure 8 shows the different rain intensities applied, from 1 to 24 hours.

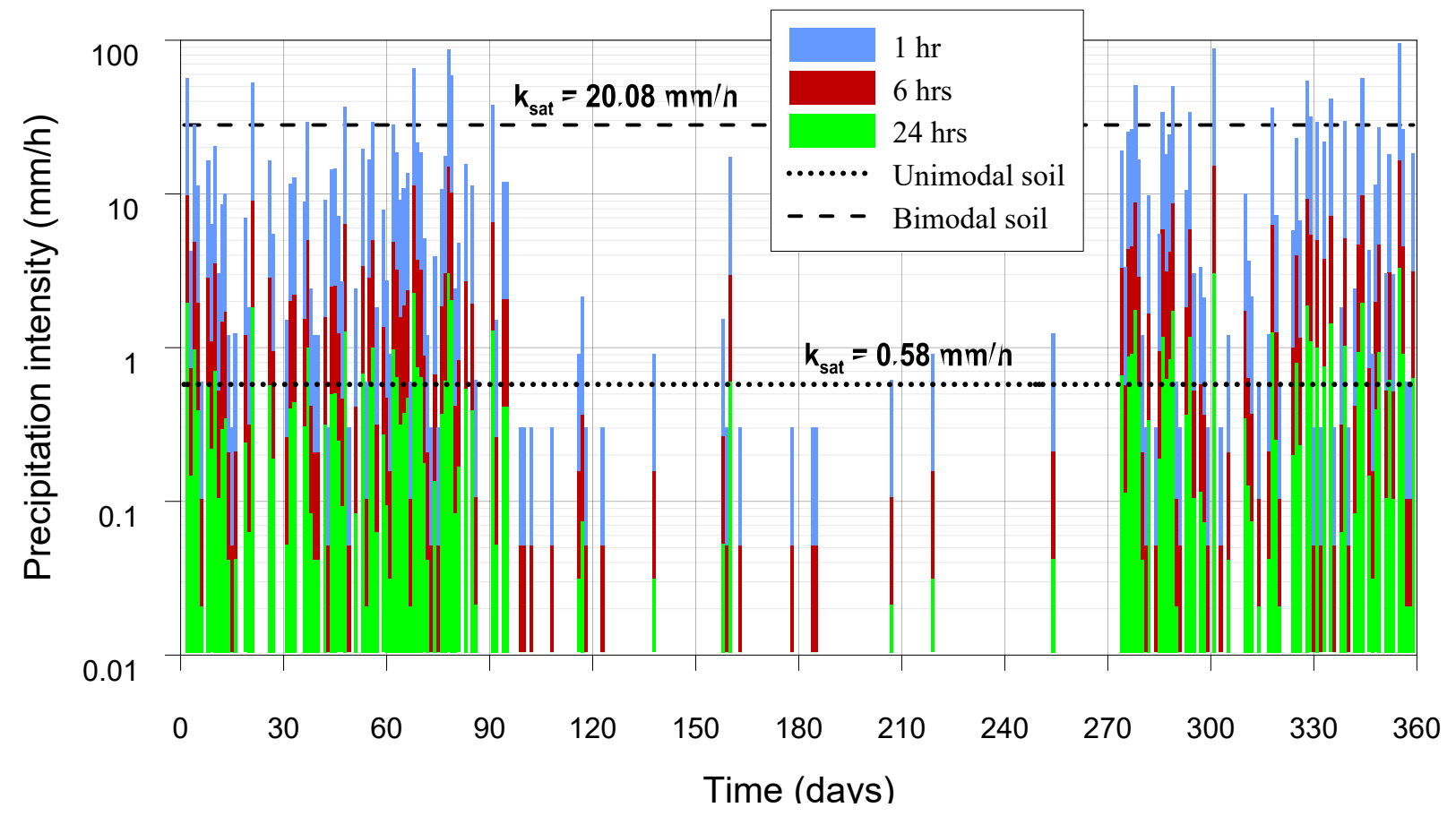

Figure 8 Relationship between rain intensities and saturated permeability of surface materials

Cases S1 and S4 were analysed, as they are composed of different materials in their surface layers. The surface layer in S1 consists of the bimodal soil with permeability of $28.08 \mathrm{~mm} / \mathrm{h}$ and the surface material of the $\mathrm{S} 4$ case is the unimodal soil with permeability of $0.58 \mathrm{~mm} / \mathrm{h}$. Figure 8 allows a preliminary qualitative evaluation of the runoff. This evaluation is possible because the saturated permeability represents the maximum rate of infiltration of the soil. Figure 8 shows that even for the heaviest rains, there should be no significant runoff when the bimodal soil is used in the upper layer. In the case of unimodal soil, much higher runoff volumes are expected.

The preliminary observations based on Figure 8 can be re-evaluated on the basis of the water balance of cases S1 and S4, obtained from the numerical analyses and presented in Figures 9 and 10, respectively. During the period of analysis, the presence of rainy season between days 0 and 100 and another rainy period between days 275 and 300 is observed. It is observed that the actual evaporation curves begin to distance themselves from the potential evaporation curves when the drought period begins, which is explained by the increase in suction and consequent difficulty in withdrawing water from the system. 

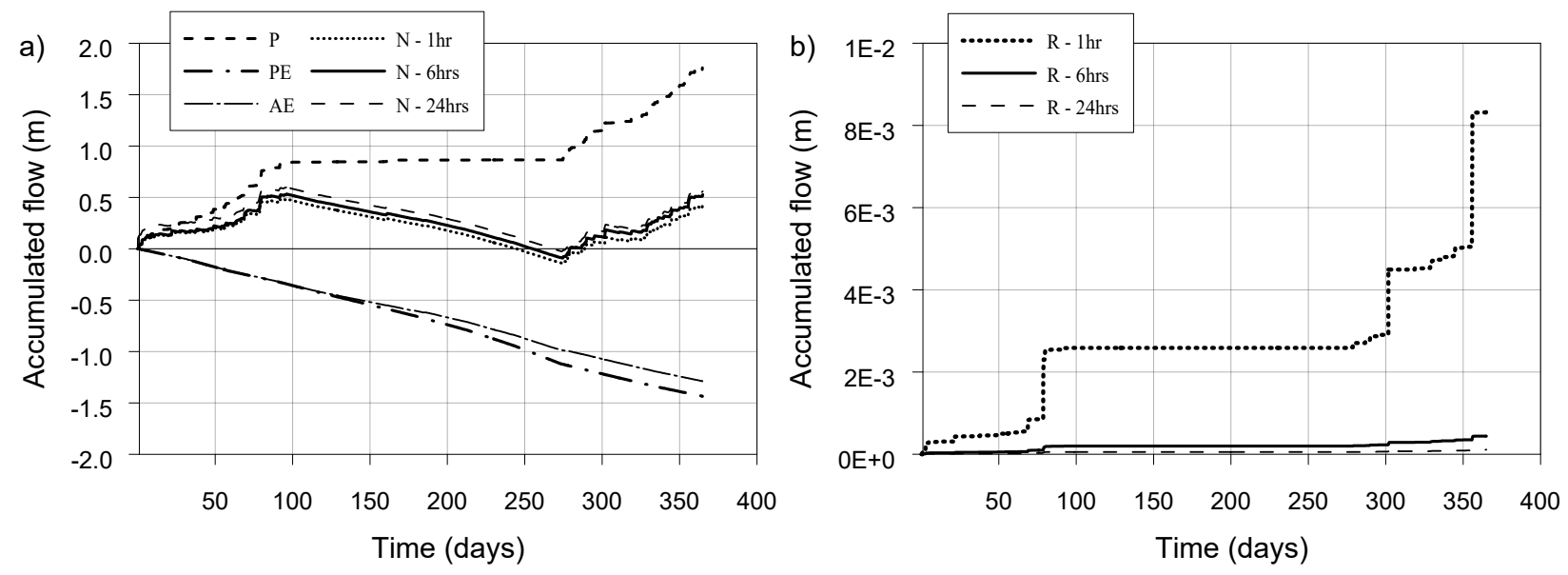

Figure 9 Water balance for different rain durations for Case S1: (a) all components; (b) runoff
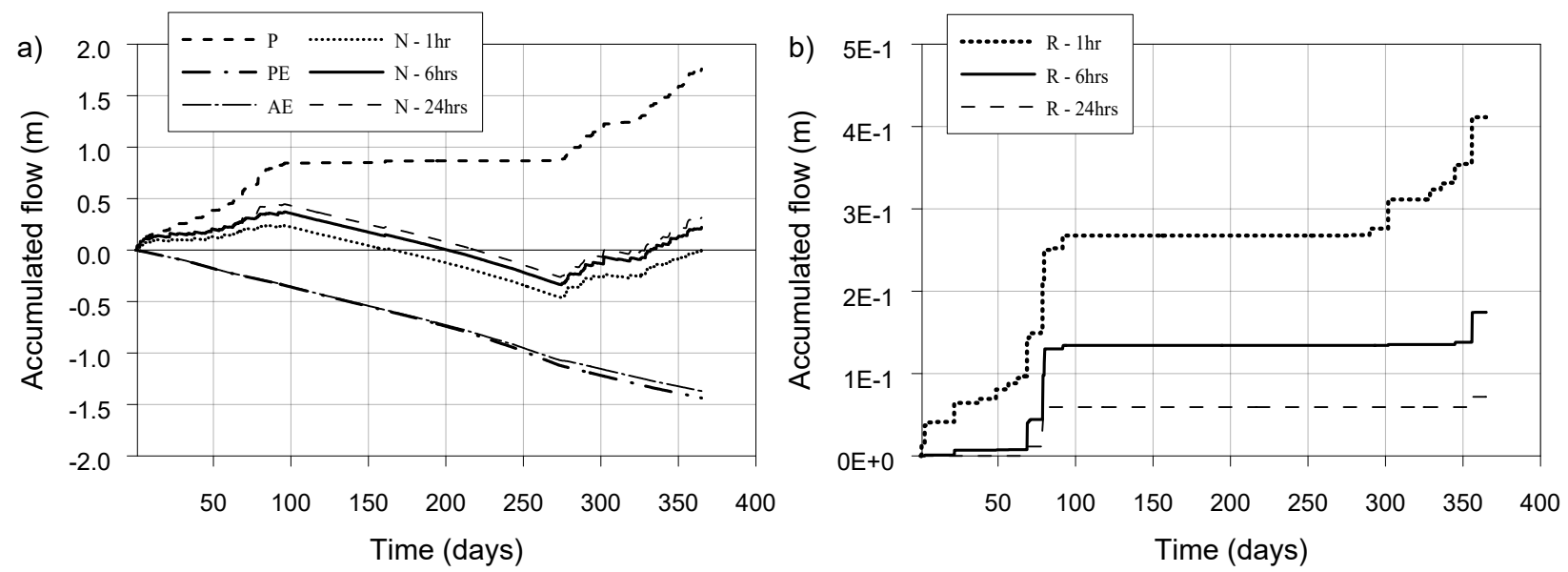

Figure 10 Water balance for different rain durations for Case S4: (a) all components; (b) runoff

Another flow component represented in the water balances is the net flow at the soil-atmosphere boundary (N) which corresponds to the amount of water that enters or leaves the system. It is observed in Figures 9 and 10 that there is a subtle difference between the flow curves at the soil-atmosphere boundary $(\mathrm{N})$ when subjected to rains of different intensities. The 24-hour rainfall is the least intense and results in more infiltration. The 1-hour rain produces the highest intensity and results in the lowest values of infiltration. It is also observed that the accumulated values of actual evaporation did not change significantly as a function of rainfall intensities. This result, however, should not be generalised, because changes in infiltration rates should affect suctions and, as a result, influence actual evaporation.

The influence of rainfall duration can also be observed when analysing the runoff $(R)$, as shown in Figures $9(b)$ and 10 (b). Precipitations with longer duration and consequently lower intensity results in the lowest surface runoff. It is also observed that, for Case S1, precipitations lasting 6 and 24 hours produce negligible surface runoff while considering the duration of 1 hour resulted in a relatively higher volume. The effects of the different intensities were more significant for Case S4. In addition to observing a smaller infiltrated volume, in relation to Case S1, it is also observed larger runoffs resulting for all the duration values of applied rains.

The differences in the amount of infiltrated water may influence the porewater pressures at the top of the systems, as shown in Figure 11. The larger suctions maintained at the top of the system for the $\mathrm{S} 4$ case are a consequence of the shape of the SWCC. In the case of the S1 system, the bimodal soil undergoes suction variations of 10 to $10,000 \mathrm{kPa}$ for a short range of moisture changes. It is also interesting to observe that during almost all the duration of the year, the moisture changes corresponds to the water stored in the macropores. In the case of the unimodal soil used in the S4 system, the smaller amplitude of suctions is the result of the higher air-entry value of this material. It is observed that the suction at the cover surface for 
1-hour rains is higher due to lower amounts of infiltration. However, such porewater pressure differences are not significant during periods of drought, producing actual evaporation that is independent of rainfall duration.
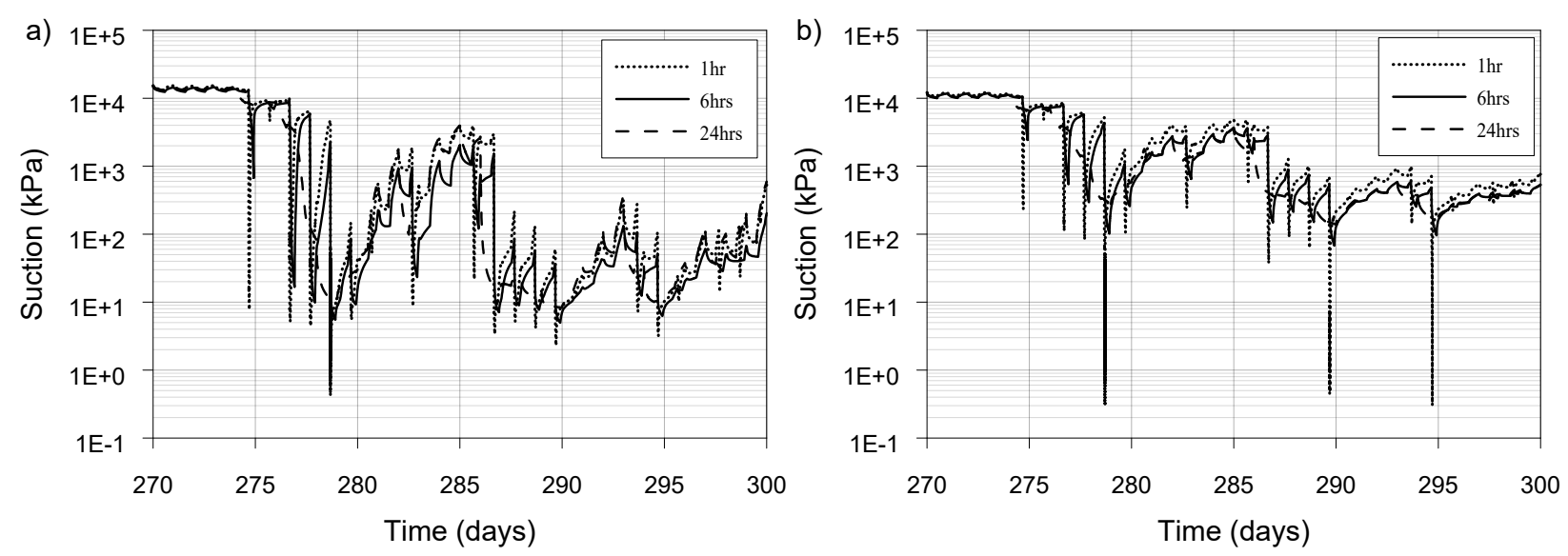

Figure 11 Suctions at the cover surface for different precipitation durations: (a) Case S1; (b) Case S4

Figure 12 shows the accumulated flow that reaches the tailings for the different rain intensities. The figure shows that the worst scenario is the 24-hour rainfall, which shows a significantly larger volume reaching the tailings. Likewise, the most favourable situation would be the consideration of 1-hour rainfalls, as the infiltrated volume is smaller. The results show that only the S4 system, with rain of 1 hour, presents a deficit of stored water volume after one complete hydrological year. This means that, while in other scenarios the system would fail repeatedly over consecutive hydrological years, in Case S4 the cover system has the potential to perform increasingly better. Another relevant observation is that the feasibility of the S1 and S4 systems seems to be dependent on the amount of surface runoff. It should also be noted that considering the typical climate of the region studied, a 24-hour rainfall would be very conservative, since such rainfall duration is uncommon. At the same time, considering a 1-hour rainfall would be non-conservative, as this rain duration would require less complex geometry, and system performance may fail over time. Thus, the precipitation duration adopted in the remaining analyses presented herein will be the 6-hour rainfall.
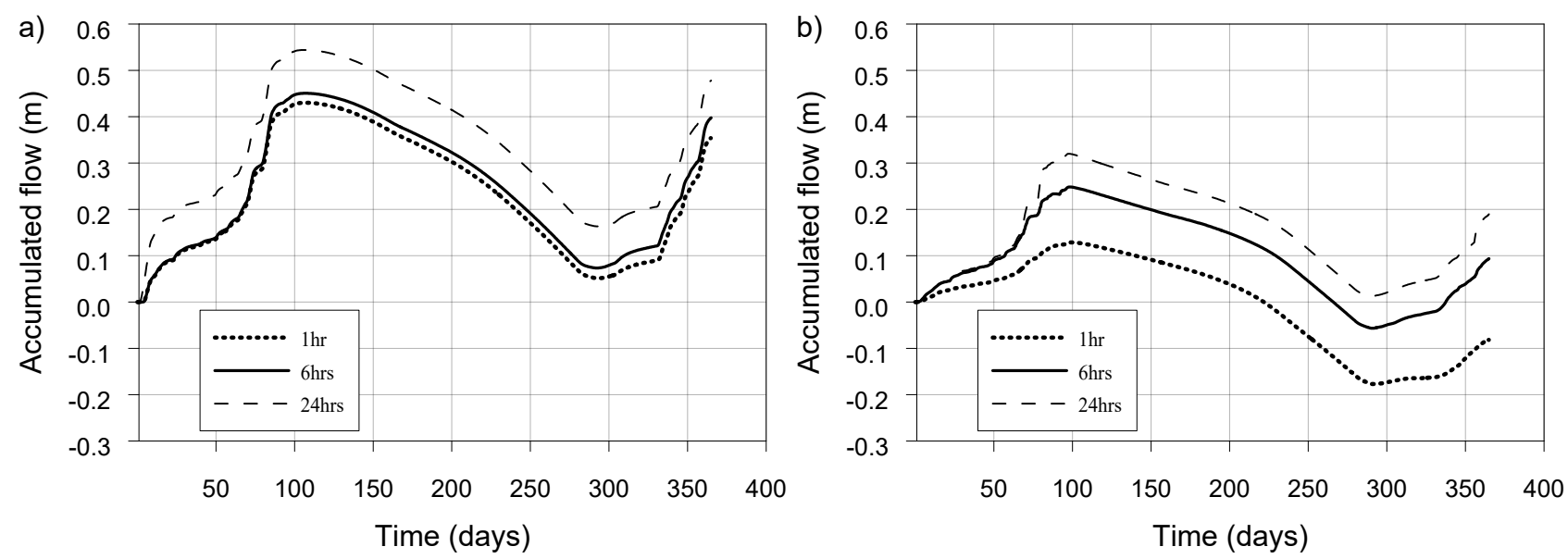

Figure 12 Flows at the cover-waste interface for different rainfall durations: (a) Case S1; (b) Case S4

\subsection{Water balance for all cover systems}

Figure 13 shows the water balances obtained for Cases S1, S2, S3 and S4. Cases S2 and S3 show a subtle approximation of the AE and PE curves, in relation to Case S1. Considering that the surface material of all three cases is the same, this behaviour of the $A E$ and PE curves may be due to the decrease in the thickness of the cover layer, promoting the removal of water from the system by evaporation. 

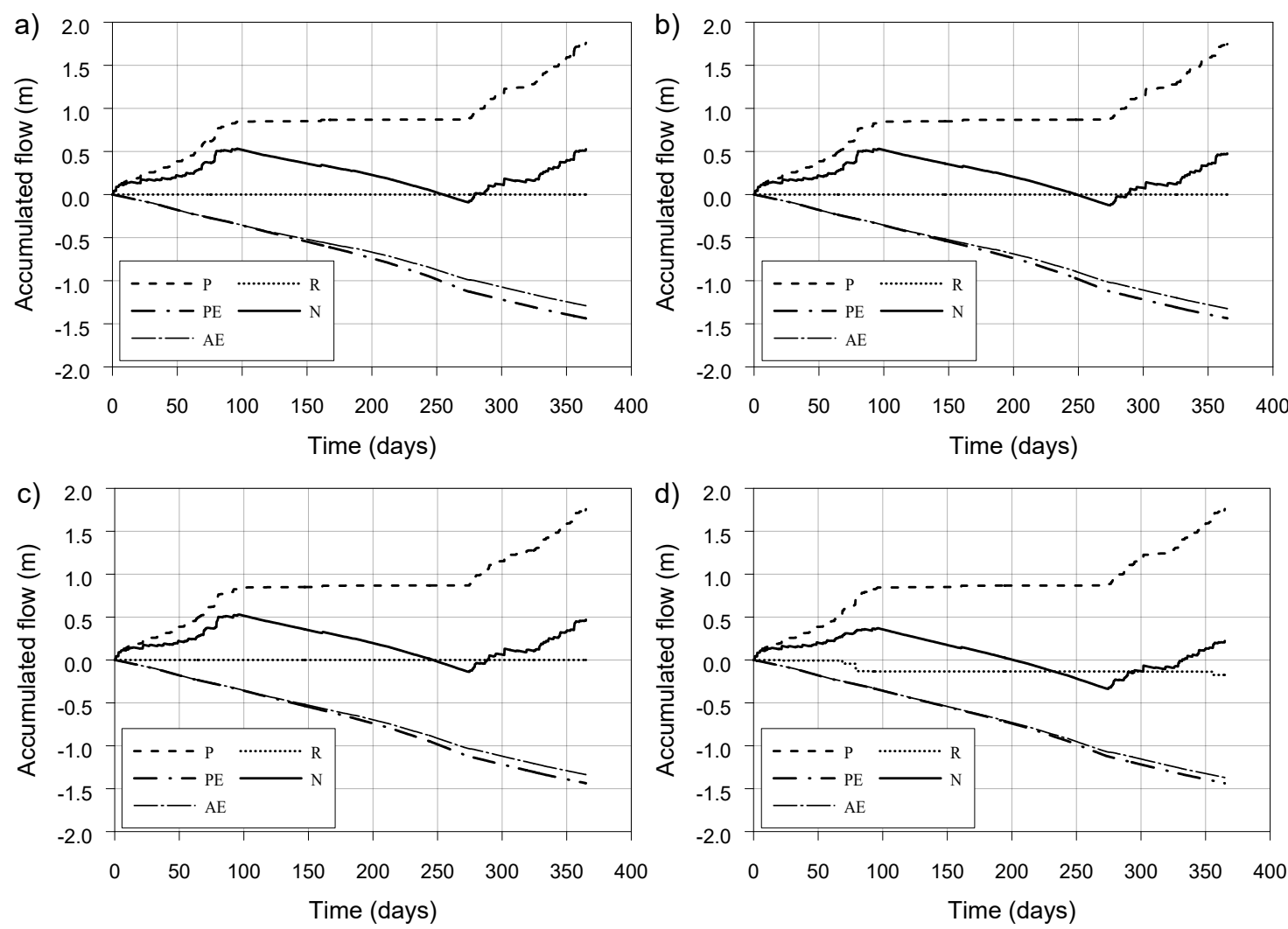

Figure 13 Water balance for cover systems: (a) Case S1; (b) Case S2; (c) Case S3; (d) Case S4

Cases S2 and S3 have nearly identical net flux results. This was somewhat expected, since the surface layers of the two cases have the same material and the same thickness. It cannot be concluded, however, that similar water balances result in similar amounts of infiltration into the tailings layer. For this, it is necessary to evaluate the internal flow, which may have been affected by the presence of the low permeability and capillary barriers. Finally, the water balance of Case S4 presented a clear reduction in the amount of water infiltrated in the system, due to the increased runoff.

Table 2 presents the accumulated flow expressed as a percentage of the average annual precipitation of $1,760 \mathrm{~m}$. From these results it is possible to confirm that the best system among the four proposed is $\mathrm{S} 4$. The superior performance of Case 4 is due to the low permeability of the surface layer, which causes greater volume of runoff and a consequent reduction of the volume infiltrated. Storage capacity of the cover system plays a secondary role. Analysing the data regarding the volume of precipitation that was retained by the system, it is observed that the values are practically the same for all cases.

Table 2 Relation between precipitated volume and flow in the system

\begin{tabular}{lcccc}
\hline Case & $\begin{array}{c}\text { Precipitation } \\
\text { (\%) }\end{array}$ & $\begin{array}{c}\text { Surface liquid } \\
\text { flow (\%) }\end{array}$ & $\begin{array}{c}\text { Entry into } \\
\text { waste pile (\%) }\end{array}$ & $\begin{array}{c}\text { Retention in } \\
\text { the cover (\%) }\end{array}$ \\
\hline S1 & 100 & 43 & 23 & 7 \\
S2 & 100 & 28 & 22 & 5 \\
S3 & 100 & 27 & 20 & 7 \\
S4 & 100 & 13 & 5 & 7 \\
\hline
\end{tabular}




\section{Conclusion}

The performance of a cover system is dependent on several factors that must be considered during design. For example, the choice of a tropical bimodal soil as a cover for cases S1, S2 and S3 did not offer a good solution, since this soil has a very low air-entry value, resulting in poor storage capacity and hindering the system ability to act as a storage and release medium. The use of tropical soil only produces good performance if used in a compacted condition, as demonstrated by Case S4. The superior performance of cover S4 is mainly due to the low permeability of the surface material. However, the use of a compacted layer with the thickness used in Case S4 would make the cover system costlier. Regarding the performance of the capillary sand barrier applied to cases S2 and S4, it was not possible to observe significant benefits of capillary barriers in the systems. The $\mathrm{S} 2$ case was shown to be the worst case in terms of storage capacity. The proposed systems were analysed for a period of only one year. To verify the performance of these systems, analyses considering the entire life spam of the cover system is advised, to evaluate the influence of the moisture accumulation or depletion over the years. Finally, since the possible combination of materials are numerous, the proposed systems could be further optimised.

\section{References}

Adu-Wusu, C \& Yanful, EK 2006, 'Performance of engineered test covers on acid-generating waste rock at Whistle mine, Ontario,' Canadian Geotechnical Journal, vol. 43, no. 1, pp. 1-18.

Amorim, NR 2008, Evaluation of the Performance of Cover Systems in the Rio Paracatu Mining Mine (RPM), PhD thesis, Federal University of Viçosa, Viçosa.

Angelim, RR 2011, Pressiometric Test Performance in Compacted Embankments of Earth Dams in the Estimation of Geotechnical Parameters, PhD thesis, University of Brasília, Brasília.

Camargo, AP \& Camargo, MBP 2000, 'An analytic revision of the potential evapotranspiration', Brangantia, vol. 50, no. 2, pp. 125-137.

Collischonn, W \& Tassi, R 2008, Introduction to Hydrology, 5th edn, Federal University of Rio Grande do Sul, Rio Grande do Sul.

Duarte, LB 2012, Numerical evaluation of the design of cover systems for the closure of reservoirs for disposal of mining waste, Masters thesis, University of Minas Gerais, Belo Horizonte.

Fredlund, DG 2002, 'Use of soil-water characteristic curves in the implementation of unsaturated soil mechanics', in JFT Jucà, TMP de Campos \& FAM Marinho (eds), Proceedings of the Third International Conference on Unsaturated Soils, vol. 3, A.A. Balkema, Rotterdam.

Fredlund, DG \& Rahardjo, H 1993, Soil Mechanics for Unsaturated Soils, John Wiley \& Sons, New York.

Fredlund, DG \& Gitirana Jr, GFN 2005, 'Unsaturated soil mechanics as a series of partial differential equations', Proceedings of the International Conference on Problematic Soils, Eastern Mediterranean University, Famagusta, pp. 3-30.

Fredlund, DG, Xing, A \& Huang, S 1994, 'Predicting the permeability function for unsaturated soils using the soil-water characteristic curve', Canadian Geotechnical Journal, vol. 31, pp. 533-546.

Gitirana Jr, GFN, Carvalho, ETL, Nascimento, BB \& Cordão Neto, MP 2012, 'Modeling the flow of water and air in unsaturated soils' in JC Carvalho, GFN Gitirana Jr \& ETL Carvalho (eds), Topics on Infiltration: Theory and Practice Applied to Tropical Soils, Technology College, Brasília.

Gitirana Jr, GFN \& Fredlund, DG 2004, 'Soil-water characteristic curve equation with independent properties', Journal of Geotechnical and Geoenvironmental Engineering, vol. 130, no. 2, pp. 209-212, https://doi.org/10.1061/(ASCE)1090-0241(2004)130:2(209)

Gitirana Jr, GFN, Fredlund, DG \& Lima, MCG 2006, 'Fluxo em solos não saturados e o processo erosivo', in JC Carvalho, MM Sales, NM Souza \& MTS Melo (eds), Erosive Processes in the Brazilian Midwest, FINATEC, Brasília.

Interstate Technology \& Regulatory Council (ITRC) 2003, Technical and Regulatory Guidance for Design, Installation, and Monitoring of Alternative Final Landfill Covers, ALT-2, Washington, D.C., Interstate Technology \& Regulatory Council, Alternative Landfill Technologies Team.

Kühn, VO 2014, Shear Resistance of a Tropical Unsaturated Soil Considering High Suctions, master thesis, Federal University of Goiás, Goiânia.

Leão Carvalho, ET 2013, Geotechnical Evaluation of Stormwater Infiltration Wells, PhD thesis, University of Brasília, Brasília.

Matos, THC 2011, Hydro-Mechanical Characterization of Fosfogesso and Soil-Phosfogesso Mixtures, Masters thesis, University of Brasília, Brasília.

MEND 2004, Design, Construction and Performance Monitoring of Cover Systems for Waste Rock and Tailings, Ottawa.

O'Kane, MA, Ayres, B, Christensen, D \& Meiers, G 2002, CETEM Manual on Cover System Design for Reactive Mine Waste, O'Kane Consultants Inc., Saskatoon.

PDE Solutions Inc. 2008, FlexPDE, version 5.0, computer software, Antioch.

Silva Júnior, AC 2015, Probabilistic Rhythmic Approach Applied in Flow Analysis and Stability of Slopes, PhD thesis, University of Brasília, Brasília.

Silva, PAD 2011, Study of the Capillary Barrier Phenomenon: Numerical Modeling and Physical Experimentation, PhD thesis, University of Minas Gerais, Belo Horizonte.

Wilson, GW 1990, Soil Evaporative Fluxes for Geotechnical Engineering Problems, PhD thesis, University of Saskatchewan, Saskatoon, 464 p. 
